\title{
Village malaria worker performance key to the elimination of artemisinin-resistant malaria: a Western Cambodia health system assessment
}

Sara E. Canavati ${ }^{1,2^{*}}$, Saranath Lawpoolsri ${ }^{3}$, Cesia E. Quintero², Chea Nguon ${ }^{4}$, Po Ly ${ }^{4}$, Sasithon Pukrittayakamee ${ }^{1,5}$, David Sintasath ${ }^{6}$, Pratap Singhasivanon ${ }^{3}$, Koen Peeters Grietens ${ }^{7,8,9}$ and Maxine Anne Whittaker ${ }^{10,11}$

\begin{abstract}
Background: Village malaria workers (VMWs) and mobile malaria workers (MMWs) are a critical component of Cambodia's national strategy to eliminate Plasmodium falciparum malaria by 2025. Since 2004, VMWs have been providing malaria diagnosis through the use of rapid diagnostic tests and free-of-charge artemisinin-based combination therapy in villages more than $5 \mathrm{~km}$ away from the closest health facility. They have also played a key role in the delivery of behaviour change communication interventions to this target population. This study aimed to assess the job performance of VMWs/MMWs, and identify challenges they face, which may impede elimination efforts.

Methods: A mixed-methods assessment was conducted in five provinces of western Cambodia. One hundred and eighty five VMW/MMW participants were surveyed using a structured questionnaire. Qualitative data was gathered through a total of 60 focus group discussions and 65 in-depth interviews. Data triangulation of the qualitative and quantitative data was used during analysis.

Results: Overall, VMWs/MMWs met or exceeded the expected performance levels (80\%). Nevertheless, some performance gaps were identified. Misconceptions regarding malaria transmission and prevention were found among workers. The recommended approach for malaria treatment, directly-observed treatment (DOT), had low implementation rates. Stock-outs, difficulties in reaching out to migrant and mobile populations, insufficient means of transportation and dwindling worker satisfaction also affected job performance.

Discussion: VMW/MMW job performance must be increased from 80 to $100 \%$ in order to achieve elimination. In order to do this, it is recommended for the national malaria programme to eliminate worker malaria knowledge gaps. Barriers to DOT implementation and health system failures also need to be addressed. The VMW programme should be expanded on several fronts in order to tackle remaining performance gaps. Findings from this evaluation are useful to inform the planning of future activities of the programme and to improve the effectiveness of interventions in a context where artemisinin drug resistance is a significant public health issue.
\end{abstract}

Keywords: Community malaria worker, Artemisinin resistance, Cambodia, Malaria elimination, Health system strengthening

\footnotetext{
*Correspondence: s.canavatidelatorre@kellogg.oxon.org; sara.canavati@ burnet.edu.au

${ }^{1}$ Department of Clinical Tropical Medicine, Faculty of Tropical Medicine, Mahidol University, 420/6 Ratchawithi Road, Ratchathewi, Bangkok 10400, Thailand

Full list of author information is available at the end of the article
} 


\section{Background}

Improving access to diagnosis and treatment and providing appropriate health education for at-risk populations are essential components of successful malaria control [1]. Access to early detection and treatment can be improved through the deployment of community health workers. Since the Alma Ata Declaration in 1978, international efforts to improve access to primary health care have shifted towards the deployment of various types of community health workers (CHWs). Worldwide, malaria community-based interventions by CHWs have successfully improved health outcomes and decreased malaria mortality in resource-poor settings [2-4].

CHWs can play a crucial role in addressing health workforce shortages, especially in rural and remote areas of the country [2], as has been the case for Cambodia. Amongst the ten countries that comprise the Association of Southeast Asian Nations (ASEAN), Cambodia has the greatest sub-national inequities in its distribution of medical doctors [5]. Most public health facilities in Cambodia are under-staffed, or lack health providers who can deliver appropriate services in rural and remote areas [6]. Villagebased volunteer workers have played an important role in malaria diagnosis and treatment in many different settings for more than 35 years. Two of these programmes stand out in terms of their size and longevity: the Volunteer Collaborator Network of Latin America [7] and the Village Voluntary Malaria Collaborator Programme of Thailand [8]. The success of these programmes has been attributed to the cultural tradition of community participation and sustained commitment already present in these regions, as well as to support from national malaria control programmes. Small, established rural communities in Cambodia also have a strong tradition of community participation in political decision-making, both among ethnic minorities [9] and in the general population, save for a brief disruption during the Khmer Rouge era [10,11].

Following a pilot phase, the village malaria worker (VMW) project was launched in 2004 as a National Programme for Parasitology, Entomology and Malaria Control (CNM)-led scheme [12]. It provided essential supplies for VMWs to access communities in remote villages. Within the then-labelled "containment zones", VMWs targeted the general population, whereas mobile malaria workers (MMWs) targeted the migrant population. At that point in time, a high level of poor health indicators in target communities justified this focused and vertical approach. By 2008, 400 of the most malariaendemic communities in Cambodia were being provided early malaria diagnosis and treatment through the village-based volunteer network. The project was initially seen as a medium-term venture that would be scaled down in accordance with the gradual expansion and strengthening of static health services. Nevertheless, it was later expanded to provide a surveillance and education function, which has become integral to Cambodia's malaria elimination efforts.

Under the Bill \& Melinda Gates Foundation-funded and World Health Organization (WHO)-led (2007-2009) strategy for containment of artemisinin-resistant Plasmodium falciparum parasites in South-East Asia [13], the CNM and other partners endeavoured to contain the spread of artemisinin-resistant (ART-R) P. falciparum parasites. Recently, Cambodia set itself the ambitious goal of eliminating falciparum malaria by 2025 [14]. At present, this elimination effort is focused on those provinces in which ART-R elimination zones are located. Within the containment project, the VMW project was significantly expanded in ART-R zones 1 and 2. Over a period of only 2 years, the number of VMW-assisted villages was increased three-fold, from 400 to 1123 villages. In these containment zones, VMW responsibilities had a strong focus on Directly Observed Therapy (DOT), screening, and treatment (Fig. 1).

\section{Methods}

In order to evaluate the quality and scope of VMW activities within the containment project zones, as well as the challenges VMWs/MMWs face, a mixed methods assessment was conducted in five Western Cambodian provinces. The objectives of this study were to: (i) appraise VMW and MMW job satisfaction; (ii) assess their performance according to their job descriptions; and (iii) gain insight into the challenges inherent in delivering diagnosis, treatment and health education activities at the community level.

\section{Qualitative strand}

\section{Data collection and sampling}

The qualitative assessment was conducted in five provinces, including 36 villages and eight health centres (HCs). Qualitative data were gathered through a total of 60 focus group discussions (FGDs) (416 participants) and 65 in-depth interviews (IDIs) conducted between October 2011 and January 2012. The semi-structured part of the qualitative data collection instruments (i.e. FGD and IDI guides) were initially developed based on the authors' previous work [15] and on the health belief model [16], which was further adapted for the purpose of this study.

FGD and IDI participants included VMWs and MMWs, public health facility staff, village chiefs, villagers, migrants, and malaria patients. Purposive sampling was used to select participants to ensure gender distribution, a variety of ages, geographical provenances, intra-provincial travel capacity, migration statuses and occupations. 
The VMW role is to:

1. attend all training and refresher training sessions;

2. provide diagnosis and treatment;

3. keep proper records;

4. ensure that he or she keeps adequate stocks;

5. attend the monthly meeting at the health centre;

6. immediately refer to the nearest health centre any patient with signs of severe malaria and any patient who has repeat signs of malaria within one month of initial treatment;

7. participate in other malaria control activities, including health education and vector control activities;

8. quickly inform the health centre if there is any unusual increase in the number of cases of malaria;

9. assist the health facility staff in organizing and carrying out the mass screening and treatment (MSAT) campaigns;

10. implement Directly Observed Treatment (DOTs); and

11. assist the health facility staff with village mapping exercises

Fig. 1 VMW roles and responsibilities

\section{Focus group discussions}

A total of 36 village-based FGDs were conducted in VMW-assisted villages. For (i) FGDs with community members, two villages were purposively selected for geographical balance per HC. As male and female community members have different risks and vulnerabilities (e.g. tendency for forest work), in each village two male and two female FGDs were conducted. Each villagebased FGD consisted of eight participants $(n=32)$. (ii) Additional male and female FGDs were conducted with migrant workers, consisting of eight participants $(\mathrm{n}=16)$. (iii) FGDs with $V M W s / M M W s$ were also conducted. In order to have sufficient participants for the farm-based FGDs, VMWs/MMWs were selected, based on operational district (OD) rather than HC. Each VMW/MMW FGD consisted of eight participants $(n=16)$; two male and two female FGDs were conducted per OD.

\section{In-depth interviews}

Selection criteria for all IDIs was for participants to: (1) have been a resident of the community for at least 2 years, in order to ensure that they had been exposed to the VMW programme for some period of time; (2) be between 25-45 years of age, as this age range is most exposed to malaria in the study site [17-20].

For both FDGs and IDIs, community members, migrant workers, and the village chief were interviewed in each selected village. In each health centre, the HC staff, $V M W s, M M W s$ were interviewed.

\section{Data analysis}

FDGs and IDIs were recorded, fully transcribed, and translated into English. Data analysis consisted of examining, categorizing, tabulating or recombining the data, in order to address the study's initial aim. Thematic analysis around the key themes of the project was undertaken using Nvivo $9^{\circledR}$ software; transcripts were read and re-read for themes that emerged from the data. These themes were clustered to form overarching, larger themes. Triangulation and critical case analysis added rigour to the process.

\section{Quantitative strand Data collection and sampling}

A cross-sectional study was carried out, using a structured questionnaire. The sample size was calculated based on an expected $80 \% \mathrm{VMW} / \mathrm{MMW}$ job performance rate, with a $5 \%$ acceptable error. With a total of 534 VMWs and $108 \mathrm{MMWs}$ in the five selected provinces, a type I error of 0.05 , and a $10 \%$ estimated nonresponse rate, it was calculated that a total of $196 \mathrm{VMWs}$ and MMWs were required for the study.

Subsequently, five ODs within the five provinces were randomly selected and stratified by zone (two ODs from Zone 1 and three ODs from Zone 2). Within these ODs, all HCs with 10 or more VMWs or MMWs were selected as potential sites for sample recruitment. All VMWs and MMWs within those HCs were asked to participate in the study, as per exhaustive sampling. About $95 \%$ of those 
VMWs and MMWs were included in the study; the other $5 \%$ did not attend the survey.

\section{Data analysis}

Data were double-entered using an Epi Info ${ }^{\circledR}$ database. Analysis was performed using Stata ${ }^{\circledR}$ version 11 (StataCorp LP, College Station, TX, USA). Descriptive statistics, including basic frequencies and simple proportions, were calculated. The Mantel-Haenszel Chi square test or the Fisher's exact test was used to calculate significance.

\section{Ethical issues}

Ethical clearance was obtained from the Cambodian National Ethics Committee for Health Research in August 2011 (130NECHR) and from the Ethics Committee of the Faculty of Tropical Medicine of Mahidol University (MUTM 2012-021-01). Local authorities (village leader and commune chief) and community leaders were informed of the purpose and expected duration of the study.

For the qualitative strand, the interviewers followed the Code of Ethics of the American Anthropological Association (AAA). As proposed by the AAA, all interviewees were informed before the start of the interview about project's goals, the topic and type of questions, the intended use of results for scientific publications, and their right to refuse the interview, interrupt the conversation at any time, and withdraw all given information during or after the interview. Anonymity was guaranteed and the confidentiality of interviewees assured by assigning a unique code number to each informant. Written consent was obtained. Each survey participant provided informed written consent before participation. Participant's approval and cooperation was sought in every aspect of data collection. A mid-term data collection meeting was conducted in Phnom Penh, where the team leaders met with the team coordinator to discuss progress and address challenges.

\section{Results}

In the qualitative strand, a total of 65 IDIs were conducted among farm owners, MMWs, VMWs, malaria patients, HC staff, community members and village chiefs. From each selected commune in the catchment area, the staff member responsible for coordinating $\mathrm{VMW} / \mathrm{MMW}$ activities and assessing VMW/MMW performance was also interviewed.

In the cross-sectional quantitative survey, 185 participants responded to the survey (response rate of $94.7 \%$ ). The majority were Khmer (98\%), most were married (82\%), and half had completed primary education. Farming was their most common profession (92\%). $58 \%$ were male, and the mean age was 35 . Overall, most worker performance indicators were in line with the expected level of performance $(80 \%)$, or even higher (Table 1 ).

\section{Malaria knowledge \\ Worker education}

The majority (90.0 \%) of VMW and MMW participants reported having received the original two-day training in 2009, and refresher training in 2011 (99.5\%). Although more than $33 \%$ of them lived at a considerable distance from the nearest $\mathrm{HC}$, most (99.5\%) said they regularly attended monthly meetings at the $\mathrm{HC}$, as required by their job description. These monthly meetings are part of the continued professional development of the workers, and all the VMWs/MMW interviewed found the monthly meetings useful (Table 1).

The respondents were asked about malaria symptoms, treatment and transmission. Symptom recall was high (Table 2), and $99 \%$ of VMWs and MMWs said that a blood test is necessary to confirm malaria diagnoses. $83.3 \%$ of the interviewees understood that not taking the recommended anti-malarial drug regimen can increase parasite resistance. Respondents also recalled that patients who fail to complete treatment regimens can relapse (particularly in Zone $1, \mathrm{P}=0.026$ ), or continue to transmit parasites (particularly in Zone 2, $\mathrm{P}=0.051$ ) (Table 3). All respondents knew that malaria is transmitted through mosquito bites. Likewise, risk behaviours, such as sleeping without a mosquito net, and prevention strategies, like wearing protective clothing, had high recall rates. The latter was reported at a statistically significantly higher level in Zone 1 than in Zone 2 (Fig. 2).

Overall, more than $15 \%$ of the answers reflected misconceptions about malaria transmission. Infection sources were sometimes reported to include poor hygiene (6.1\%), dirty drinking water (4.6\%), unboiled water (3.6\%), and bad food (1.0\%). $20.8 \%$ of the total participants deemed boiling water to be a preventive measure (Table 3). This misconception, confirmed by qualitative interviews, was most prevalent in Zone 2. This statement, from an FGD with VMWs, was typical:

My education methods are: Firstly, I recommend them to drink boiled water. Secondly, to wear long clothing. Thirdly, I ask them not to chat [outdoors] after the sunset. If they want to chat, they must do so under the mosquito nets to prevent malaria. (FGD15_VMW_Male).

\section{Migrant education}

The qualitative interviews indicated that migrants were provided with health education comparable to that of the local population. Nevertheless, many VMWs and MMWs 
discussed how newly-arrived migrants are often unaware of basic preventive measures, and contract malaria shortly after their arrival, before they receive health education. No MMWs, and only one VMW, reported having provided pre-departure malaria education. HC staff supported this observation, strongly recommending that health education be provided to prospective migrants at the pre-departure stage, while they still reside in nonendemic areas. They emphasized that in order to do this, VMW coverage would need to be extended to malariafree zones.

\section{Barriers to job performance}

The VMW/MMW job description includes eleven activities for which they are held accountable. The qualitative and quantitative strands found significant hindrances to these activities in the following areas:

\section{Adherence to DOT guidelines}

According to most VMWs and MMWs, they routinely observed the first dose of treatment (98.48\%), in accordance with DOT guidelines. However, DOT on the second and third days of treatment, which is also required by the guidelines, was reportedly adhered to by only $56.8 \%$ of respondents. Both VMWs and MMWs appeared to face similar barriers to DOT implementation. According to the quantitative data, a lack of available transportation was one of the main challenges, as workers must often cover long distances in order to reach patients' homes. This transportation problem was significantly more likely to be cited as a barrier in Zone $1(\mathrm{p}=0.000)$, and was linked to a more frequent reporting of long distances as a problem in Zone $1(\mathrm{p}=0.001)$ (Table 4).

In addition to their own restricted mobility, VMWs and MMWs reported high patient mobility as a barrier to providing DOT. There was therefore a prevailing perception amongst workers that it is not possible to provide DOT to mobile and migrant populations (MMPs), which was associated with the general agreement that providing malaria education and resources like insecticide-treated mosquito nets to migrants before they migrate is crucial. These perceptions were found in the qualitative interviews, where a typical discussion was:

We sometimes give migrants malaria drugs to take for 3 days, but after they take the drugs for only 2 days they move somewhere else. They might look for drugs in other places. We do not know whether they recovered or not. (FGD37_VMW_MaLE).

\section{Table 1 Indicators pertaining to VMWs/MMWs compared with assessment results}

\begin{tabular}{|c|c|}
\hline Process and outcome indicators & Assessment results \\
\hline $\begin{array}{l}\% \text { of contact points (based on initial situ- } \\
\text { ational analysis) providing malaria diagnosis, } \\
\text { treatment, prevention, and messages to } \\
\text { mobile/migrant populations }\end{array}$ & Most VMWs and MMWs reported working with mobile and migrant groups: 179/197 = 91.0\% \\
\hline $\begin{array}{l}\text { All VMWs and MMWS are fully trained accord- } \\
\text { ing to plan by 06/09 }\end{array}$ & The majority of VMWs and MMWs received training during the year 2009: 178/197 = 90.3 \% \\
\hline $\begin{array}{l}\% \text { of community level staff (VMW/MMW) are } \\
\text { aware of key messages }\end{array}$ & $\begin{array}{l}\text { Seek treatment from VMW or HC: } 167 / 197=88.36 \% \\
\text { Sleep under an ITN: } 161 / 197=85.2 \% \\
\text { Sleep under a net when visiting the forest: } 132 / 197=69.8 \% \\
\text { Sleep under a net when travelling: } 94 / 197=49.7 \% \\
\text { Seek treatment within } 24 \text { h: } 39 / 197=20.6 \% \\
\text { Complete anti-malarial treatment: } 33 / 197=17.5 \% \\
\text { Aware of three key messages: } 102 / 197=51.8 \%^{\mathrm{a}} \\
\text { Aware of four key messages: } 63 / 197=32.0 \%{ }^{\mathrm{b}}\end{array}$ \\
\hline $\begin{array}{l}\text { \% of community level staff (VMW/MMW) who } \\
\text { perform according to the TOR }\end{array}$ & $\begin{array}{l}\text { Findings for the fourth indicator \% of VMWs and MMWs who perform according to TOR are described below } \\
\text { 1. The VMW shall keep proper records of consultations, diagnosis and treatment on the standard forms } \\
\text { All VMW/MMW reported filling out the monthly list of cases }=100 \% \\
\text { 2. The VMW shall attend the monthly meeting at the health centre where he or she will provide the } \\
\text { health care staff with the record forms and pick up a re-supply of RDTs and anti-malarial drugs } \\
\text { Nearly all VMWS and MMWs reported attending the monthly meetings at the health centre on a monthly } \\
\text { basis = } 196 / 197=99.5 \% \\
\text { 3. The VMW must immediately refer to the nearest health centre any patient with signs of severe } \\
\text { malaria and any patient who has repeat signs of malaria within } 1 \text { month of initial treatment } \\
\text { It was reported that the main group that gets referred are severe malaria patients } 122 / 197=82.43 \%\end{array}$ \\
\hline
\end{tabular}

\footnotetext{
a Three key messages include: seek treatment from VMW or HC; sleep under an ITN; and sleep under a net when visiting the forest

b Four key messages include: seek treatment from VMW or HC; sleep under an ITN; sleep under a net when visiting the forest and sleep under a net when travelling
} 
Table 2 Malaria symptom recall by VMWs and MMWs

\begin{tabular}{ll}
\hline Symptoms & \% of VMWs/MMWs \\
\hline Malaria symptoms & \\
Fever & 86.8 \\
Chills & 82.2 \\
Headache & 79.2 \\
Sweating & 75.6 \\
Severe malaria symptoms & \\
Unconsciousness & 83.8 \\
High temperatures & 77.7 \\
Convulsions & 65.5 \\
Very pale skin & 55.8 \\
\hline
\end{tabular}

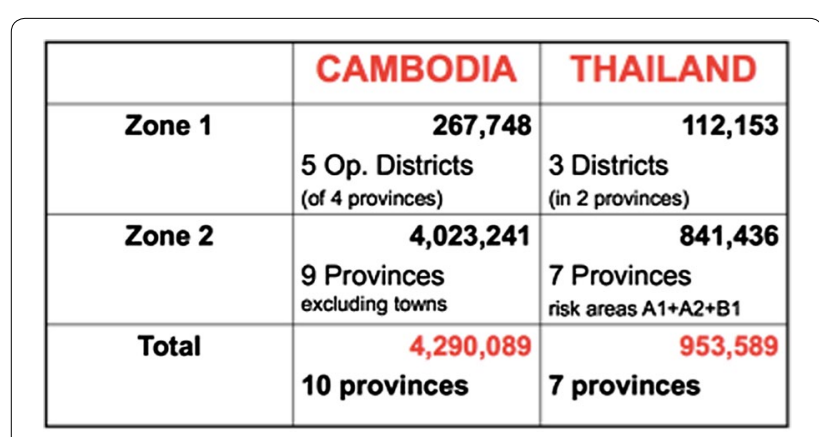

Fig. 2 Target populations in the containment project

\section{Accessibility to patients}

HC staff indicated that the VMWs' geographical proximity to their catchment community significantly increased the feasibility and effectiveness of malaria treatment, particularly when it comes to providing timely outreach education, treatment, and patient follow-up, all of which are pillars of the malaria programme. VMWs were more likely to report being available for consultations in the mornings, and workers were more likely to undertake proactive case finding at that time. In Zone 1, VMW availability for consultations was reported to be significantly higher than in Zone 2. A significantly higher proportion of pregnant women and children under 5 years of age were referred to the HC in Zone 1 as well, and VMWs were more available for consultations ( $p$ value 0.011 ) (Tables 5, 6). VMWs or public health facilities were more likely to provide the message "seek treatment for malaria from a VMW or public health facility" $(P$ value $=0.001)$ in Zone 1 (Table 7).

Servicing MMPs appeared to be particularly challenging in both zones There are six specific difficulties when working with migrant people. Firstly, migrant people do not have permanent housing. For example, they live under tents in the forest. Secondly, they do not have mosquito nets, and allow themselves to be bitten by mosquitoes. Thirdly, their food is insufficient. Fourthly, they are far away from health services. They also lack means of transportation. Lastly, we do not know their exact accommodation. (FGD15_VMW_Male).

$76.7 \%$ of MMWs and VMWs in Zone 1, which contains a higher number of remote villages, and $75.6 \%$ in Zone 2, expressed major difficulties posed by long-distance travel. Because VMWs and MMWs found it so difficult to reach out to MMPs themselves, they frequently requested that village chiefs take on this role.

\section{Management of health resources}

Most VMWs and MMWs reported following correct storage practices for medications $(81.2 \%)$ and rapid diagnostic tests (RDTs) $(79.7 \%)$. When asked about stock outs in the last 3 months, $57.4 \%$ reported that RDTs had been out of stock for more than a week, and anti-malarials for even greater periods of time. The interviewees stated that $84.3 \%$ of stock outs were caused by a lack of supply from the $\mathrm{HC}$, and $61.2 \%$ were caused by unexpected demand. In the qualitative interviews, workers discussed how during stock-outs, patients experience interrupted or delayed treatment before the VMW/MMW's monthly restocking trip. In some instances, patients were initially referred to the HC. Nevertheless the HCs are far, and have restricted opening hours, which coincide with the patients' own working hours. Many patients reported that they bypassed the $\mathrm{HC}$ for this reason, and went directly to the private sector. Patients who lacked the funds to do this often used traditional medicine. Some VMWs, out of concern, used their own resources to help patients travel to the HC. Stock-outs make adherence by workers to the national treatment guidelines difficult or impossible; some discussed using other anti-malarial treatments available in the community in order to provide some care:

Sometimes we have to buy anti-malarials from private clinics, as we are out of stock. In this case we have to charge the patient, and treatment is no longer free of charge, as they mentioned to us upon recruitment. We get blamed by patients, as they have to spend money for treatment. (FGD43_VMW_Female).

Stock outs impact more than quality of care. Community members expressed dissatisfaction at having to go to the $\mathrm{HC}$ for anti-malarials or tests during stock outs. VMWs/MMWs expressed concern that these shortages erode the community's trust in them, which then results in reduced patient motivation to access their services. 
Table 3 Knowledge of malaria reported by VMWs and MMWs by zone

\begin{tabular}{|c|c|c|c|c|c|c|c|}
\hline & \multicolumn{2}{|c|}{ Overall $\mathrm{N}=197$} & \multicolumn{2}{|c|}{ Zone $1 \mathrm{~N}=71$} & \multicolumn{2}{|c|}{ Zone $2 \mathrm{~N}=126$} & \multirow[t]{2}{*}{$P$ value } \\
\hline & $n$ & (\%) & $\mathrm{n}$ & $(\%)$ & $\mathrm{n}$ & $(\%)$ & \\
\hline At least three key malaria symptoms ${ }^{a}$ & 92 & 46.7 & 40 & 56.3 & 61 & 48.4 & 0.521 \\
\hline At least four key malaria symptoms ${ }^{b}$ & 74 & 37.6 & 26 & 36.6 & 48 & 38.1 & 0.837 \\
\hline \multicolumn{8}{|l|}{ Determinants of malaria illness } \\
\hline Blood test (slide or dipstick) & 195 & 99.0 & 71 & 100.0 & 124 & 98.4 & 0.190 \\
\hline Symptoms & 57 & 28.9 & 19 & 26.8 & 38 & 30.2 & 0.614 \\
\hline Previous experience & 22 & 11.2 & 5 & 7.0 & 17 & 13.5 & 0.286 \\
\hline Doctor's examination & 3 & 1.5 & 0 & 0.0 & 3 & 1.5 & 0.168 \\
\hline Other & 4 & 2.1 & 1 & 1.4 & 3 & 2.4 & 0.642 \\
\hline Don't know & - & 0.0 & - & 0.0 & - & 0.0 & - \\
\hline At least three key signs and symptoms of severe malariac & 88 & 44.7 & 35 & 49.3 & 53 & 42.1 & 0.327 \\
\hline At least four key signs and symptoms of severe malaria ${ }^{d}$ & 48 & 24.4 & 18 & 25.4 & 30 & 23.8 & 0.809 \\
\hline \multicolumn{8}{|l|}{ Ways to get malaria } \\
\hline Mosquito bites & 197 & 100 & 71 & 36.0 & 126 & 64.0 & - \\
\hline Sleeping in forest without a net & 93 & 47.2 & 36 & 38.7 & 57 & 61.3 & 0.461 \\
\hline No sleep under a mosquito net & 91 & 46.2 & 31 & 34.1 & 60 & 65.9 & 0.593 \\
\hline Visiting forest & 77 & 39.1 & 29 & 37.7 & 48 & 62.3 & 0.704 \\
\hline Poor hygiene & 12 & 6.1 & 3 & 25.0 & 9 & 75.0 & 0.411 \\
\hline Drinking dirty water & 9 & 4.6 & 5 & 7.04 & 4 & 3.17 & 0.212 \\
\hline Not boiling water & 7 & 3.6 & 2 & 2.8 & 5 & 3.9 & 0.675 \\
\hline Bad food & 2 & 1.0 & 1 & 1.4 & 1 & 0.8 & 0.679 \\
\hline Other ${ }^{\mathrm{e}}$ & 3 & 1.5 & 0 & 0.0 & 3 & 2.38 & 0.593 \\
\hline \multicolumn{8}{|l|}{ Ways to prevent malaria } \\
\hline Sleep under a mosquito net & 182 & 92.4 & 63 & 88.7 & 119 & 94.4 & 0.147 \\
\hline Use treated mosquito net & 180 & 91.4 & 68 & 95.8 & 112 & 88.9 & 0.098 \\
\hline Wear covered clothing & 155 & 78.7 & 62 & 87.3 & 93 & 73.8 & 0.026 \\
\hline Burn leaves & 32 & 16.2 & 9 & 12.7 & 23 & 18.3 & 0.308 \\
\hline Stay out of forest & 15 & 7.6 & 7 & 9.9 & 8 & 6.4 & 0.373 \\
\hline Repellent & 5 & 2.5 & 2 & 2.8 & 3 & 2.3 & 0.852 \\
\hline Mosquito coil & 2 & 1.0 & 2 & 2.8 & 0 & 0.0 & 0.058 \\
\hline Insecticide spray & 1 & 0.5 & 9 & 12.7 & 23 & 18.3 & 0.308 \\
\hline Boil water & 41 & 20.8 & 12 & 16.9 & 29 & 23.0 & 0.310 \\
\hline Take medicine & 1 & 0.5 & 1 & 1.41 & 0 & 0.0 & 0.182 \\
\hline Other $^{f}$ & 38 & 19.3 & 8 & 11.27 & 30 & 23.8 & 0.032 \\
\hline \multicolumn{8}{|c|}{ Consequences of not taking the anti-malarial drugs for the recommended treatment regimen } \\
\hline Parasite will become resistant & 164 & 83.3 & 59 & 83.1 & 105 & 83.3 & 0.966 \\
\hline Patient gets sick again & 155 & 78.7 & 62 & 83.1 & 93 & 73.8 & 0.026 \\
\hline Patient does not recover & 93 & 47.2 & 31 & 43.7 & 62 & 49.2 & 0.454 \\
\hline Patient will continue to transmit malaria & 78 & 39.6 & 26 & 36.6 & 52 & 41.3 & 0.522 \\
\hline Parasite remains in the body & 76 & 38.6 & 21 & 29.6 & 55 & 43.7 & 0.051 \\
\hline Nothing & 1 & 0.51 & 0 & 0.0 & 1 & 0.8 & 1.000 \\
\hline Other $^{\mathrm{a}}$ & 7 & 3.55 & 0 & 0.0 & 7 & 5.7 & 0.051 \\
\hline \multicolumn{8}{|l|}{ a Three key malaria symptoms include: fever, chills, and headache } \\
\hline \multicolumn{8}{|c|}{ b Four key malaria symptoms include: fever, chills, headache, and sweating } \\
\hline \multicolumn{8}{|c|}{ ' Four key symptoms of severe malaria include: unconscious, very hot, and convulsions } \\
\hline \multicolumn{8}{|c|}{${ }^{d}$ Four key symptoms of severe malaria include: unconscious, very hot, convulsions, and very pale skin } \\
\hline e Other include: wearing short sleeves & & & & & & & \\
\hline
\end{tabular}




\section{Job satisfaction Motivating factors}

VMWs and MMWs reported being highly motivated to perform their job as a volunteer, and being committed to the aim of malaria elimination in Cambodia. Motivating factors included the fact that they are making a contribution to malaria control in the community (50.8\%), the social responsibility they feel to help others $(31.5 \%)$, and the benefits of attaining new skills and knowledge (17.3\%). Over $90 \%$ reported that they would want to continue to provide malaria services even if the VMW project were to conclude. Respondents also described being motivated because the community showed confidence in the quality of their work. All but one reported that patients accept and trust them to provide good quality malaria services, and that this volunteer job has increased their personal standing in the community.

\section{Worker satisfaction}

The majority of VMWs/MMWs (84\%) were satisfied that the programme increased community malaria awareness, and all but one respondent felt adequately supported by HC staff. Nevertheless, VMWs and MMWs reported that as malaria infections decline in this region, there are fewer opportunities for them to use their practical skills, which negatively impacted their motivation. Limited access to resources essential to their job, such as petrol, transportation, and tools like satchels or bags, were also said to demotivate. Similarly, respondents lacked sufficient information, education and communication (IEC) materials to support the delivery of key malaria messages, without which they found it difficult to provide effective education. Other factors that appeared to affect their motivation were a lack of supervisory visits and feedback from their line managers, and stock outs.

Trust and appreciation from the community was a strong motivating factor for the workers. Nevertheless, they reported that this is often eroded when a patient presenting with fever and other malaria symptoms tests negative for malaria. Protocol dictates that such patients must be referred to the nearest $\mathrm{HC}$, which is often inaccessible. Patients want and sometimes demand treatment from VMWs/MMWs for other illnesses, and workers are frustrated when they cannot provide it. Due to the reduction in malaria prevalence, this scenario is increasingly common. VMWs stated that their decreased malaria

Table 4 Practices: treatment and DOT

\begin{tabular}{|c|c|c|c|c|c|c|c|}
\hline \multirow[t]{2}{*}{ Treatment } & \multicolumn{2}{|c|}{ Overall N = 197} & \multicolumn{2}{|c|}{ Zone $1 \mathrm{~N}=71$} & \multicolumn{2}{|c|}{ Zone $2 \mathrm{~N}=126$} & \multirow[t]{2}{*}{$P$ value } \\
\hline & n & $(\%)$ & $\mathrm{n}$ & $(\%)$ & $\mathrm{n}$ & (\%) & \\
\hline \multicolumn{8}{|l|}{ Place where malaria patients get treated } \\
\hline At VMW/MMW's home & 193 & 98.0 & 71 & 100.0 & 122 & 96.8 & 0.129 \\
\hline At the patient's home & 156 & 79.2 & 61 & 85.9 & 95 & 75.4 & 0.081 \\
\hline Other $^{\mathrm{a}}$ & 2 & 1.02 & 0 & 0.0 & 2 & 1.6 & 0.286 \\
\hline \multicolumn{8}{|c|}{ Malaria patient is directly-observed for the first dose of medication } \\
\hline Yes & 194 & 98.5 & 70 & 98.6 & 124 & 98.4 & 0.693 \\
\hline No & 2 & 1.0 & 1 & 1.4 & 1 & 0.79 & \\
\hline Sometimes & 1 & 0.5 & 0 & 0 & 1 & 0.79 & \\
\hline \multicolumn{8}{|c|}{ Malaria patient is directly-observed for the 2 nd and 3 rd days of treatment } \\
\hline Yes & 112 & 56.9 & 35 & 49.3 & 77 & 61.1 & 0.265 \\
\hline No & 27 & 13.7 & 12 & 16.9 & 15 & 11.9 & \\
\hline Sometimes & 58 & 29.4 & 24 & 33.8 & 34 & 27.0 & \\
\hline \multicolumn{8}{|c|}{ Barriers faced when providing directly-observed treatment } \\
\hline Problem of transportation to patients'home & 151 & 76.7 & 65 & 91.6 & 86 & 68.3 & 0.000 \\
\hline Long distance to patients home & 149 & 75.6 & 63 & 88.73 & 86 & 68.3 & 0.001 \\
\hline Self-treatment & 26 & 13.2 & 5 & 7.0 & 21 & 16.7 & 0.055 \\
\hline The patient disagreed & 24 & 12.2 & 10 & 14.1 & 14 & 11.1 & 0.540 \\
\hline No knowledge of malaria drug resistance & 21 & 10.7 & 5 & 7.0 & 16 & 12.7 & 0.217 \\
\hline Treatment with other providers & 3 & 1.5 & 0 & 0.0 & 3 & 2.4 & 0.190 \\
\hline Other ${ }^{c}$ & 2 & 1.0 & 0 & 0.0 & 2 & 1.0 & 0.286 \\
\hline Don't know ${ }^{b}$ & 11 & 5.6 & 0 & 0.0 & 11 & 8.7 & 0.537 \\
\hline
\end{tabular}

\footnotetext{
a Other includes: farm, rice field

b Fisher exact test was used to calculate for significance

c Other include: death, more severe, waste of time
} 
Table 5 Case finding and referrals by zone

\begin{tabular}{|c|c|c|c|c|c|c|c|}
\hline \multirow[t]{2}{*}{ Practices } & \multicolumn{2}{|c|}{ Overall N = 197} & \multicolumn{2}{|c|}{ Zone $1 \mathrm{~N}=71$} & \multicolumn{2}{|c|}{ Zone $2 \mathrm{~N}=126$} & \multirow[t]{2}{*}{ P valu } \\
\hline & $\mathbf{n}$ & $(\%)$ & $\mathbf{n}$ & (\%) & $\mathbf{n}$ & (\%) & \\
\hline \multicolumn{8}{|c|}{ Ways in which VMW/MMW find malaria cases in their villages } \\
\hline Conduct home visits & 157 & 79.7 & 61 & 85.9 & 96 & 76.2 & 0.103 \\
\hline Malaria suspects know me and come to my house & 154 & 78.2 & 52 & 73.2 & 102 & 80.1 & 0.208 \\
\hline Other people refer them & 105 & 53.3 & 41 & 57.8 & 64 & 50.8 & 0.348 \\
\hline Conduct health education activities & 100 & 50.8 & 39 & 54.9 & 61 & 48.4 & 0.38 \\
\hline During campaigns conducted by NGOs & 2 & 1.0 & 0 & 0.0 & 2 & 1.6 & 0.286 \\
\hline Other & 4 & 2.0 & 0 & 0.0 & 4 & 3.17 & 0.129 \\
\hline \multicolumn{8}{|l|}{ Refer malaria cases to the health centre or hospital } \\
\hline Yes & 148 & 75.1 & 50 & 70.4 & 98 & 77.8 & 0.404 \\
\hline No & 49 & 24.9 & 21 & 29.6 & 28 & 22.2 & \\
\hline \multicolumn{8}{|l|}{ Who gets referred } \\
\hline Severe malaria cases & 122 & 82.4 & 41 & 82.0 & 81 & 82.7 & 0.921 \\
\hline Pregnant women & 47 & 31.8 & 21 & 42.0 & 26 & 26.5 & 0.056 \\
\hline The elderly & 44 & 29.7 & 15 & 30.0 & 29 & 29.6 & 0.959 \\
\hline Children under five & 37 & 25.0 & 17 & 34.0 & 20 & 20.4 & 0.071 \\
\hline Patients who's life is at risk & 28 & 18.9 & 11 & 22.0 & 17 & 17.4 & 0.494 \\
\hline Other $^{\mathrm{a}}$ & 30 & 20.3 & 7 & 14.0 & 23 & 33.5 & 0.175 \\
\hline \multicolumn{8}{|l|}{ Barriers faced when referring severe malaria to the $\mathrm{HC}$} \\
\hline Lack of transportation & 130 & 87.8 & 45 & 90.0 & 85 & 86.7 & 0.565 \\
\hline Long distance & 98 & 66.2 & 34 & 68.0 & 64 & 65.3 & 0.743 \\
\hline Lack of money & 67 & 42.3 & 18 & 36.0 & 49 & 50.0 & 0.106 \\
\hline The patient disagrees & 29 & 19.6 & 13 & 26.0 & 16 & 16.3 & 0.161 \\
\hline Lack of understanding of severity of disease & 17 & 11.5 & 6 & 12.0 & 11 & 11.2 & 0.889 \\
\hline Treatment with other providers & 10 & 6.8 & 2 & 4.0 & 8 & 8.2 & 0.34 \\
\hline Self-treatment & 5 & 3.4 & 1 & 2.0 & 4 & 4.1 & 0.507 \\
\hline Other ${ }^{b}$ & 4 & 2.7 & 0 & 0.0 & 4 & 4.1 & 0.148 \\
\hline
\end{tabular}

a Other includes: patient with multiple illnesses, patient with negative blood test, not malaria cases. Patients also get referred when there is blood test error and VMWs and MMWs medicine is out of stock

b Other includes: medicine was out of stock, negative blood test, never have barriers, and never have problems

caseloads would allow them to take on other responsibilities, and they felt this would help them maintain trust from the communities they served, and improve their own motivation to work.

\section{Discussion}

This is the first assessment of the VMW programme carried out within catchment areas with confirmed ART-R in Western Cambodia [21]. The assessment found, overall, competent job performance compared to the workers' benchmarked indicators (above $80 \%$ ) according to their terms of reference. Nevertheless, the elimination of falciparum malaria will require $100 \%$ performance, as cases of untreated or incompletely treated malaria are important factors in the development of anti-malarial resistance [22, 23]. For this reason, each and every case that the VMW programme is unable to treat successfully, whether due to organizational or health system failures, or dwindling worker motivation, is potentially exacerbating the spread of ART-R, and therefore compromising malaria elimination. Studies have shown that in other malaria-endemic countries, CHWs face similar system deficiencies to those identified in this study, and that these significantly interfere with the effectiveness of malaria interventions [24-27]. In order to improve the performance of Cambodia's VMW network, it is recommended that the following areas be addressed:

\section{Worker malaria knowledge}

The study found that, overall, the majority of VMWs and MMWs correctly understand malaria transmission. Nevertheless there is a sizeable minority of workers who confuse malaria prevention methods with the prevention of other health issues, a situation that has also been observed in Ethiopia, Tanzania and Bangladesh [28-33]. Given the high level of trust that communities place in 
Table 6 General information on consultations by zone

\begin{tabular}{|c|c|c|c|c|c|c|c|}
\hline \multirow[t]{2}{*}{ General information on consultations } & \multicolumn{2}{|c|}{ Total N = 197} & \multicolumn{2}{|c|}{ Zone $1 \mathrm{~N}=71$} & \multicolumn{2}{|c|}{ Zone $2 \mathrm{~N}=126$} & \multirow[t]{2}{*}{$P$ value } \\
\hline & n & $(\%)$ & $\mathbf{n}$ & $(\%)$ & n & $(\%)$ & \\
\hline \multicolumn{8}{|l|}{ Days per week spent on working as a VMW/MMW } \\
\hline 1 day & 6 & 3.05 & 3 & 4.2 & 3 & 2.4 & 0.702 \\
\hline $2-3$ days & 138 & 70.1 & 51 & 71.8 & 87 & 69.1 & \\
\hline 4-6 days & 37 & 18.8 & 13 & 18.3 & 24 & 19.1 & \\
\hline Whole week & 16 & 8.1 & 1 & 5.6 & 12 & 9.5 & \\
\hline \multicolumn{8}{|l|}{ Daily hours spent working as a VMW/MMW } \\
\hline $1 \mathrm{~h}$ & 44 & 22.3 & 16 & 22.5 & 28 & 22.2 & 0.242 \\
\hline $2-3 h$ & 132 & 67.0 & 47 & 66.2 & 85 & 67.5 & \\
\hline $4-5 h$ & 16 & 8.1 & 8 & 11.3 & 8 & 6.4 & \\
\hline 6 or $>6 h$ & 5 & 2.5 & 0 & 0.0 & 5 & 4.0 & \\
\hline \multicolumn{8}{|l|}{ Time of the day available for consultations ${ }^{a}$} \\
\hline Morning time & 170 & 86.3 & 67 & 94.4 & 103 & 81.8 & 0.013 \\
\hline Afternoon time & 132 & 67.0 & 51 & 71.8 & 81 & 64.3 & 0.280 \\
\hline Evening & 144 & 73.1 & 52 & 73.2 & 92 & 73.0 & 0.973 \\
\hline All day ${ }^{b}$ & 8 & 4.1 & 0 & 0.0 & 8 & 6.4 & 0.053 \\
\hline \multicolumn{8}{|l|}{ Time people come to VMW/MMW for consultation ${ }^{c}$} \\
\hline Morning time & 173 & 87.8 & 67 & 94.4 & 106 & 84.1 & 0.035 \\
\hline Afternoon time & 133 & 67.5 & 50 & 70.4 & 83 & 65.9 & 0.513 \\
\hline Evening & 143 & 72.6 & 52 & 73.2 & 91 & 72.2 & 0.878 \\
\hline All day & 5 & 2.5 & 0 & 0.0 & 5 & 4.0 & 0.089 \\
\hline \multicolumn{8}{|c|}{ VMW/MMW sometimes not available for consultations } \\
\hline Yes & 60 & 30.5 & 15 & 21.1 & 49 & 38.9 & 0.011 \\
\hline No & 133 & 67.5 & 56 & 78.9 & 77 & 61.1 & \\
\hline \multicolumn{8}{|l|}{ When VMW/MMW not available for consultations } \\
\hline Assign a family member/friend to assist VMW & 50 & 78.1 & 14 & 99.3 & 36 & 73.5 & 0.391 \\
\hline Refer the patient to another VMW/MMW & 6 & 9.4 & 0 & 0.0 & 6 & 12.5 & \\
\hline Refer the patient to the health centre & 3 & 4.7 & 1 & 6.7 & 2 & 4.04 & \\
\hline Ask the patient to come back on the next day & 4 & 6.3 & 0 & 0.0 & 4 & 8.2 & \\
\hline Other & 1 & 1.6 & 0 & 0.0 & 1 & 2.0 & \\
\hline
\end{tabular}

a Multiple responses possible

b Exact fisher test was performed

c Multiple responses possible

their VMWs/MMWs, addressing these misconceptions is crucial to prevent them from spreading further. The VMW network should be re-trained on key health education messages.

\section{Adherence to DOT guidelines}

DOT is a critical component of the Cambodian strategy for the containment of ART-R parasites [13]. VMWs and MMWs reported high adherence to DOT for 1st day doses, which was drastically lowered for 2nd and 3rd day doses. This was mostly attributed by workers to a lack of transportation that would enable them to visit patients, and to the difficulties in locating highly mobile patients. This study found that VMWs and MMWs tend to have a good understanding of malaria resistance and its relationship to incomplete treatment regimens. Therefore, it seems that the barriers to DOT implementation are largely logistical, not knowledge-related. Workers should be provided with the means to access remote patients; otherwise, adherence to DOT is unlikely to improve despite increased behaviour change communication (BCC) in the area.

Workers believe that DOT cannot be implemented among MMPs due to their high mobility, and requested in this study that village chiefs, who have better access to MMPs, be the ones to reach out to them. Alternatives to DOT that can ensure patient compliance among MMPs should also be explored through operational research. Two randomized controlled trials recently conducted in 
Table 7 Communication and key messages by zone

\begin{tabular}{|c|c|c|c|c|c|c|c|}
\hline \multirow[t]{2}{*}{ Communication } & \multicolumn{2}{|c|}{ Overall N = 197} & \multicolumn{2}{|c|}{ Zone $1 \mathrm{~N}=71$} & \multicolumn{2}{|c|}{ Zone $2 \mathrm{~N}=126$} & \multirow[t]{2}{*}{ P value } \\
\hline & n & (\%) & n & $(\%)$ & n & (\%) & \\
\hline \multicolumn{8}{|l|}{ In the past 1 month, VMW/MMW taught any messages or information about malaria } \\
\hline Yes & 189 & 95.9 & 70 & 98.6 & 119 & 94.4 & 0.157 \\
\hline No & 8 & 4.1 & 1 & 1.4 & 7 & 5.6 & \\
\hline \multicolumn{8}{|l|}{ Messages or information related to malaria prevention were taught or explained ${ }^{a}$} \\
\hline Malaria is caused by mosquito bites & 125 & 64.1 & 52 & 74.3 & 73 & 61.3 & 0.069 \\
\hline Wear long sleeved clothes from dusk to dawn to prevent mosquito bites & 120 & 63.5 & 39 & 55.7 & 81 & 68.1 & 0.088 \\
\hline Sleep under a mosquito net every night & 135 & 71.4 & 55 & 78.6 & 80 & 67.2 & 0.095 \\
\hline Sleep under an insecticide-treated net & 161 & 85.2 & 60 & 85.7 & 101 & 84.9 & 0.875 \\
\hline Other $^{b}$ & 26 & 14.3 & 6 & 8.6 & 21 & 17.7 & 0.085 \\
\hline \multicolumn{8}{|l|}{ Messages related to malaria diagnosis and treatment that were taught or explained } \\
\hline Seek treatment for malaria from a VMW or health facility & 167 & 88.4 & 69 & 98.6 & 98 & 82.6 & 0.001 \\
\hline Visit your village malaria worker for free malaria diagnosis and treatment & 165 & 87.3 & 61 & 87.1 & 104 & 97.4 & 0.96 \\
\hline Seek treatment for malaria promptly/within $24 \mathrm{~h}$ & 39 & 20.6 & 9 & 12.9 & 30 & 25.2 & 0.043 \\
\hline Get a blood test before taking anti-malarial drugs & 60 & 31.8 & 20 & 28.6 & 40 & 33.6 & 0.472 \\
\hline If you have fever, always seek a blood test for malaria at the nearest health facility & 48 & 25.4 & 19 & 27.1 & 29 & 24.4 & 0.672 \\
\hline Complete anti-malarial treatment & 33 & 17.7 & 7 & 10.0 & 26 & 21.9 & 0.038 \\
\hline Other & 1 & 0.5 & 0 & 0.0 & 1 & 0.8 & 0.442 \\
\hline \multicolumn{8}{|l|}{ Messages related to using and caring for mosquito nets that were taught or explained } \\
\hline Sleeping under an ITN is especially important for pregnant women & 62 & 32.8 & 27 & 38.6 & 35 & 29.4 & 0.195 \\
\hline Sleeping under an ITN is especially important for children under 5 years & 56 & 29.6 & 21 & 30.0 & 35 & 29.4 & 0.932 \\
\hline Carry and sleep under a mosquito net when travelling & 94 & 49.7 & 40 & 57.1 & 54 & 45.4 & 0.118 \\
\hline Carry and sleep under a mosquito net when visiting the forest & 132 & 69.8 & 49 & 70.0 & 83 & 65.8 & 0.971 \\
\hline The less you wash your treated net the longer it will retain its effectiveness & 119 & 63.0 & 40 & 57.1 & 79 & 66.39 & 0.204 \\
\hline Repair any holes in the net & 36 & 20.0 & 9 & 12.9 & 27 & 22.7 & 0.096 \\
\hline Other ${ }^{c}$ & 62 & 32.8 & 22 & 31.4 & 40 & 33.6 & 0.757 \\
\hline \multicolumn{8}{|l|}{ Who did VMW/MMW communicated information about malaria } \\
\hline Villagers & 196 & 99.5 & 71 & 100.0 & 125 & 99.21 & 0.452 \\
\hline Malaria patients & 114 & 57.9 & 38 & 53.5 & 76 & 60.3 & 0.354 \\
\hline Migrants/mobile population & 158 & 80.2 & 60 & 84.5 & 98 & 77.8 & 0.255 \\
\hline Friends/neighbours & 95 & 48.2 & 29 & 40.9 & 66 & 52.4 & 0.12 \\
\hline Family members & 100 & 50.8 & 32 & 45.1 & 68 & 54.0 & 0.23 \\
\hline Religious leaders/monks & 5 & 2.5 & 1 & 1.41 & 4 & 3.2 & 0.449 \\
\hline Other & 3 & 1.5 & 1 & 1.41 & 2 & 1.6 & 0.922 \\
\hline \multicolumn{8}{|l|}{ VMW/MMW has distributed or displayed any information about malaria } \\
\hline Yes & 129 & 65.5 & 48 & 67.6 & 81 & 64.3 & 0.638 \\
\hline No & 68 & 34.5 & 23 & 32.4 & 45 & 35.7 & \\
\hline \multicolumn{8}{|l|}{ Kind of information about malaria VMW/MMW displays or distributes } \\
\hline Poster & 90 & 69.8 & 34 & 70.8 & 56 & 69.1 & 0.839 \\
\hline Leaflets/brochures & 96 & 74.4 & 42 & 88.0 & 54 & 66.7 & 0.009 \\
\hline Flip charts & 27 & 20.9 & 5 & 10.4 & 22 & 27.2 & 0.024 \\
\hline Other ${ }^{d}$ & 6 & 4.7 & 0 & 0.0 & 6 & 7.4 & 0.053 \\
\hline \multicolumn{8}{|c|}{ The last time there was an event in the community that provided malaria-related health messages } \\
\hline Yesterday & 10 & 5.1 & 4 & 5.6 & 6 & 4.8 & 0.371 \\
\hline Within this week & 30 & 15.2 & 10 & 14.1 & 20 & 15.9 & \\
\hline In this month & 105 & 53.3 & 43 & 60.6 & 62 & 49.2 & \\
\hline In this year & 52 & 26.4 & 14 & 19.7 & 38 & 30.1 & \\
\hline
\end{tabular}

a Out of the total number of VMW/MMW who have taught any messages or information about malaria

b Other include: mosquito habitat elimination, blood testing, clean the surrounding, drink boiled water, eliminate mosquito habitat, fill up pond, light bonfire, know malaria symptoms, use malaria treatment, often clean water containment, use net in forest, weeding, weeding around house

c Other include: avoid drying in sunlight, do not sleep close to net, do not use net for fishing, do not wash, do not wash too often, do not wash with detergent, dry net in shade, keep away from children, keep net clean after use, keep net safe, keep net safe after use, must retreat net, put in bag after use, retreat net every 3 months, retreat net every 6 months and wash net every 6 months

d Other include: booklet, educating, malaria booklet, malaria prevention, picture calendar, pictures and videos 
Kenya showed that text message reminders can improve adherence to treatment $[34,35]$.

\section{Transportation}

Aside from VMWs and MMWs themselves, transportation difficulties also affect patients trying to access health services. Innovative transportation schemes accessible by all affected parties should be considered. Operational research may shed light on how best to address this problem, as has been suggested by the Cambodian Research Consortium [36]. Most of the current research on innovative transportation comes from maternal and child health programmes in Africa; there is little evidence regarding South-East Asia.

\section{Stock-outs}

Stock-outs can lead to both workers and patients relying on the private sector, which is particularly worrisome. Using private sector malaria medications is against the national guidelines. A recent study found that in Western Cambodia most private sector anti-malarials are either substandard or counterfeit [37]. The national programme has piloted an $\mathrm{m}$-Health system to address supply chain issues and it is now implementing it across the country. It was found to increase access to artemisininbased combination therapy and RDTs in the public sector, which in turn led to a decrease in malaria morbidity and mortality [38]. Several factors may be responsible for the stock-outs. Previous research in Cambodia has shown that VMWs tend to run out of RDTs and antimalarials more rapidly during the rainy season, due to a higher demand, or to difficulties in replenishing supplies (heavy workload in the fields, weather-related inaccessibility) [39]. Previous studies have also warned that supply chain strengthening in Cambodia, including forecasting and monitoring, is vital for VMWs to be effective [40, 41]. Treatment delays and interruptions in an ART-R context can be very detrimental to patients' prognoses and strengthen parasite resistance. In order to address supply chain weaknesses, bottlenecks will need to be clearly identified in different geographical areas within each zone, and addressed.

\section{Expansion of the VMW role}

According to this study, VMWs, MMWs, as well as community members at large, want malaria workers to diagnose and treat other diseases too. Studies in various elimination settings confirm that as malaria infections become rarer, the VMW network will increasingly need to be able to diagnose, treat, and prevent other common diseases in order to be seen as adding value to communities, and maintain worker motivation [42]. A community health worker programme integrated into the primary healthcare system can promote care at the household level and function as a crucial link between community members and the primary healthcare care system. In Cambodia, a 2008 pilot project in which VMWs provided additional health services resulted in more frequent access of VMW services by community members, and increased worker motivation. Capitalizing on this success, the role of VMWs and MMWs in Cambodia should be expanded to include acute respiratory infections and diarrhoea in children under five.

\section{Reaching mobile and migrant populations}

Determining how best to meet the needs of mobile populations should be prioritized in the national research agenda. Respondents to this study indicated that migrant workers often contract malaria shortly after their arrival because they are unfamiliar with prevention methods. They also indicated that migrants are extremely difficult to treat effectively. This is consistent with a recent survey by URC, which shows that most migrants travel from malaria-free to endemic provinces [43]. Pre-departure education, which was widely advocated by study respondents, will therefore be vital to malaria elimination. Previous efforts to implement it have had very limited success, as it is difficult to determine which individuals are about to travel and should be targeted. Predeparture education should therefore be combined with on-the-way education, which has also been piloted but not evaluated. Several respondent-driven sampling and applied anthropological studies on the Cambodia and Thailand borders [44-46] have indicated that there are significant variances in human population movement (HPM), showing the need for differential malaria control and elimination strategies within and across contexts in order to target different mobile populations [47, 48].

\section{More community health workers}

There is wide consensus that VMW coverage is lacking nationwide. The national programme is currently expanding the number of VMW villages in Cambodia, which will contribute significantly to malaria elimination efforts. Nevertheless, the VMW network should be extended to all communities beyond reasonable reach of health facilities nation-wide [12], particularly if the scope of VMW services is expanded. In addition to addressing serious health concerns like acute respiratory infections, this will help to mitigate problems caused by long distances and lack of transportation, increase the availability of VMWs for consultation during peak hours, and provide pre-departure malaria education in non-endemic areas. 


\section{Considerations when scaling up}

It is clear that other countries have benefitted from the integration of malaria integrated community case management (ICCM) with other health services. Important facilitating factors for success include interactive and practical training, clear guidelines, and regular supportive supervision [49]. Nevertheless, scaling up VMWs' expanded roles to a national level depends on the health system's capacity and readiness. Other national programmes that have reported poor supervision, variable quality of care, and stock outs of supplies and equipment, have been unable to implement adequate clinical supervision [50-53] in expanded programmes. At the same time, some CHW programmes have been scaled up too quickly, seriously undermining their quality and effectiveness $[54,55]$. Furthermore, little is known about ICCM implementation in ART-R containment settings, and there is an urgent need for more data regarding worker supervision in scaled programmes, as well as the most effective method for referring patients to HCs when malaria workers cannot treat them [49]. The national programme should consider these critical aspects before scaling up interventions. Brazil, Bangladesh and Nepal successfully scaled up their programmes gradually and deliberately, with adjustments made along the way [56].

\section{Worker motivation}

The impact of community health worker motivation on job performance is rarely explored [57-60]. Nevertheless, recent studies have shown that it plays a significant role [61-63]. This study found that VMW/MMW motivation is generally high, and efforts, discussed above, to reduce challenges and expand the VMW programme will help to maintain and improve it. Nevertheless, other demotivating factors should be eliminated. The lack of supplies necessary for day-to-day activities, like bags and IEC materials, must be addressed at the system level. More frequent performance management that focuses on showing appreciation can address the demotivating systemic lack of feedback from supervisors. Incentives such as training and career development, as well as mechanisms that allow workers to receive regular feedback from the community, can bolster respect in the community and improve worker motivation.

\section{Study limitations}

Like any survey, the results from the survey were based on what the participants had provided, which is difficult to really contrast what they said with their actual behaviour of the participants. The results only refer to HCs with 10 or more VMWs/MMWs. There could be systematic differences in performance and practice of those VMWs and MMWs working in HCs of smaller size due to, for instance, differences in training and supervision, and this deserves further evaluation.

\section{Conclusions}

Malaria control and elimination depend on high-performance levels in the health system. This high performance means delivering malaria interventions at high and equitable levels of quality, and with effective universal coverage. This will require providing geographical access to target populations, ensuring consistent high-standard care, and securing the motivation of malaria workers, as well as their logistical ability to provide services. It is important to have strong evaluation elements as the programme rolls out, in order to identify emerging challenges and obstacles, and to design appropriate measurable responses to these findings [64].

\section{Abbreviations}

ART-R: artemisinin resistant; ASEAN: Association of Southeast Asian Nations; BCC: behaviour change communication; $\mathrm{CHW}$ : community health worker; CNM: National Programme for parasitology, entomology and malaria control (Cambodia); DOT: directly-observed treatment; FGD: focus group discussion; HC: health centre; ICCM: integrated community case management; IDI: in-depth interview; IEC: information, education and communication; MMP: mobile and migrant population; MMW: mobile malaria worker; OD: operational district; RDT: rapid diagnostic test; VMW: village malaria worker; WHO: World Health Organization.

\section{Authors' contributions}

Conceived and designed the study: SEC, SLN, SP, DS, PS, MAW. Implemented the study: SEC, CN, PL, and MAW. Analysed the data: SEC. Contributed technical advice and tools for the study: SEC, SLN, CN, PL, DS, MAW. Co-wrote the paper: CEQ, KPG, MAW. Wrote the paper: SEC. All authors read and approved the final manuscript.

\section{Author details}

${ }^{1}$ Department of Clinical Tropical Medicine, Faculty of Tropical Medicine, Mahidol University, 420/6 Ratchawithi Road, Ratchathewi, Bangkok 10400 Thailand. ${ }^{2}$ Centre for Biomedical Research, Burnet Institute, Melbourne, Australia. ${ }^{3}$ Department of Tropical Hygiene, Faculty of Tropical Medicine, Mahidol University, 420/6 Ratchawithi Road, Ratchathewi, Bangkok 10400, Thailand.

${ }^{4}$ The National Center For Parasitology, Entomology and Malaria Control, Ministry of Health, Corner Street 92, Trapaing Svay Village, Sankat Phnom Penh Thmey, Khan Sensok, Phnom Penh, Cambodia. ${ }^{5}$ Mahidol-Oxford Tropical Medicine Research Unit, Faculty of Tropical Medicine, Mahidol University, 420/6 Ratchawithi Road, Ratchathewi, Bangkok 10400, Thailand. ${ }^{6}$ Malaria Consortium Asia, Faculty of Tropical Medicine, Mahidol University, 420/6 Rajavidhi Road, Room 805, Bangkok 10400, Thailand. ${ }^{7}$ Medical Anthropology Unit, Department of Public Health, Institute of Tropical Medicine, Antwerp, Belgium. ${ }^{8}$ School of Tropical Medicine and Global Health, Nagasaki University, Nagasaki, Japan. ${ }^{9}$ Partners for Applied Social Sciences (PASS) International, Tessenderlo, Belgium. ${ }^{10}$ Division of Tropical Health and Medicine, College of Public Health, Medical and Veterinary Sciences, James Cook University, Townsville, QLD 4811, Australia. ${ }^{11}$ The University of Queensland School of Public Health, Herston, QLD 4006, Australia.

\section{Acknowledgements}

We would like to thank the staff at the VMW Unit at CNM for their assistance and collaboration with field data collection. We would also like to thank the health department staff for their collaboration and assistance in data collection, and to all the individuals who kindly gave their time to participate in this study. Funding for this study was obtained from the Bill and Melinda Gates Foundation through the WHO Containment Project. We thank the reviewers for their valuable input in this paper. 


\section{Competing interests}

The authors declare that they have no competing interests.

Received: 9 October 2015 Accepted: 3 May 2016

Published online: 20 May 2016

\section{References}

1. T3: test. Treat. Track initiative. http://www.who.int/malaria/areas/test_ treat track/en/. Accessed 5 Jan 2016.

2. Haines ASD, Lehmann U, Rowe AK, Lawn JE, Jan S, et al. Achieving child survival goals: potential contribution of community health workers. Lancet. 2007;369:2121-31.

3. Perez FBH, Dastagire SG, Altmann M. The role of community health workers in improving child health programmes in Mali. BMC Int Health Hum Rights. 2009;9:28.

4. Yeung SVDW, Socheat D, White NJ, Mills A. Access to artemisinin combination therapy for malaria in remote areas of Cambodia. Malar J. 2008:7:243.

5. O'Brien P, Gostin LO. Health worker shortages and global justice. Milbank Memorial Fund. October 2011. http://www.milbank.org/uploads/documents/healthworkershortages.pdf. Accessed 1 Feb 2016.

6. LE Collins D, Stenberg K. Scaling up child survival interventions in Cambodia: the cost of national programme resource needs. Phnom Penh: World Health Organization; 2007.

7. Ruebush TK 2nd, Zeissig R, Koplan JP, Klein RE, Godoy HA. Community participation in malaria surveillance and treatment. III. An evaluation of modifications in the Volunteer Collaborator Network of Guatemala. Am J Trop Med Hyg. 1994;50:85-98.

8. Okanurak K, Sornmani S. Community participation in the malaria control program in Thailand: a review. Southeast Asian J Trop Med Public Health. 1992;23(Suppl):36-43.

9. Jacobs B, Price N. Improving access for the poorest to public sector health services: insights from Kirivong Operational Health District in Cambodia. Health Policy Plan. 2006;21:27-39.

10. Ui S, Heng L, Yatsuya H, Kawaguichi L, Akashi H, Aoyana A. Strengthening community participation at health centers in rural Cambodia: role of local non-governmental organizations (NGOs). Crit Public Health. 2010;20:97-115.

11. Pellini A, Ayres D. Community participation in local governance in Cambodia: learning from the village networks approach. Dev Pract. 2007:17:404-9.

12. Hewitt S. A review of Cambodia's village malaria worker project. Phnom Penh: World Health Organization; 2012

13. WHO/Global Malaria Programme. A strategy for the containment of artemisinin tolerant parasites in South-East Asia. Project proposal submitted to the Bill and Melinda Gates Foundation. 15 September 2008.

14. Moeun CN. Cambodian Launches national plan to eliminate malaria by 2025. 2011. https://www.malariacontainment.wordpress. com/2011/04/15/cambodia-launches-national-plan-to-eliminatemalaria-by-2025/. Accessed 4 Feb 2016.

15. Canavati SE. Community knowledge, attitudes and practices (KAP) on behaviour change communication (BCC) interventions for the control, prevention, diagnosis, and treatment of malaria among mobile and malaria populations (MMPs) in Pailin province, Western Cambodia: a quantitative and qualitative study. Faculty of Tropical Medicine, Mahidol University, Department of Clinical Tropical Medicine. 2013.

16. Hochbaum GM. Public participation in medical screening programs: a sociopsychological study. Washington: US Dept of Health, Education, and Welfare. Public Health Service Publication No. 572, 1958.

17. Dysoley L, Rithea L, Bunkea T, Babu S, Sim K, Nguon C, et al. Cambodia malaria survey 2010. Phnom Penh: National Centre for Parasitology, Entomology and Malaria Control (CNM); 2010.

18. NIPH. Cambodia national malaria survey 2004. Phnom Penh: National Institutes of Health; 2004.

19. NIPH. Cambodia malaria survey 2007. Phonm Penh: National Institute of Public Health; 2007. p. 55

20. CNM. Report of the Cambodia containment survey 2009 and 2010, vol. 1. Phnom Penh: CNM; 2010. p. 67
21. Dondorp A, Nosten F, Yi P, Das D, Phyo AP, Tarning J, et al. Artemisinin resistance in Plasmodium falciparum malaria. $N$ Engl J Med. 2009;361:455-67.

22. WHO. Global plan for artemisinin resistance containment (GPARC). Geneva: World Health Organization; 2011. p. 56-7.

23. Phyo AP, Nkhoma S, Stepniewska K, Ashley EA, Nair S, McGready R, et al. Emergence of artemisinin-resistant malaria on the western border of Thailand: a longitudinal study. Lancet. 2012;379:1960-6.

24. Blanas DA, Ndiaye Y, Nichols K, Jensen A, Siddiqui A, Hennig N. Barriers to community case management of malaria in Saraya, Senegal: training, and supply-chains. Malar J. 2013;12:95.

25. Gyapong M, Garshong B. Lessons learned in home management of malaria; implementation research in four African countries. Geneva: The Special Programme for Research and Training in Tropical Diseases; 2007.

26. Souares A, Lalou R, Sene I, Sow D, Hesran JY. Adherence and effectiveness of drug combination in curative treatment among children suffering uncomplicated malaria in rural Senegal. Trans R Soc Trop Med Hyg. 2008:102:751-8.

27. Thomson A, Khogali M, Smet M, Reid T, Mukhtar A, Peterson S. Low referral completion of rapid diagnostic test-negative patients in communitybased treatment of malaria in Sierra Leone. Malar J. 2011;10:94.

28. Abate A, Degarege A, Erko B. Community knowledge, attitude and practice about malaria in a low endemic setting of Shewa Robit Town, northeastern Ethiopia. BMC Public Health. 2013;13:312.

29. Astatkie A. Knowledge and practice of malaria prevention methods among residents of Arba Minch Town and Arba Minch Zuria District, Southern Ethiopia. Ethiop J Health Sci. 2010:20:185-93.

30. Legesse M, Deressa W. Community awareness about malaria, its treatment and mosquito vector in rural highlands of central Ethiopia. Ethiop J Health Dev. 2009;23:40-7

31. Legesse Y, Tegegn A, Belachew T, Tushune K. Knowledge, attitude and practice about malaria transmission and its preventive measures among households in Urban Areas of Assosa Zone, Western Ethiopia. Ethiop J Health Dev. 2007;21:157-65.

32. Adedotun A, Morenikeji O, Odaibo A. Knowledge, attitudes and practices about malaria in an urban community in South-western Nigeria. J Vect Borne Dis. 2010;47:155-9.

33. Kinung'hi SM, Mashauri F, Mwanga JR, Nnko SE, Kaatano GM, Malima R, et al. Knowledge, attitudes and practices about malaria among communities: comparing epidemic and non-epidemic prone communities of Muleba district, North-western Tanzania. BMC Public Health. 2010;10:395.

34. Lester RT, Ritvo P, Mills EJ, Kariri A, Karanja S, Chung MH, et al. Effects of a mobile phone short message service on antiretroviral treatment adherence in Kenya (WelTelKenya 1): a randomised trial. Lancet. 2010;376:1838-45.

35. Pop-Eleches $C$, Thirumurthy $H$, Habyarimana JP, Zivin JG, Goldstein MP, de Walque D, et al. Mobile phone technologies improve adherence to antiretroviral treatment in a resource-limited setting: a randomized controlled trial of text message reminders. AIDS. 2011;25:825-34.

36. Canavati S, Lawford H, Fatunmbi B, Lek D, Leang R, Top Samphor N, et al. The Cambodia Research Consortium: expediting research for malaria elimination with the emergency response to artemisinin resistance framework. Malar J. 2016;15:5.

37. Phanouvong S, Raymond C, Krech L, Dijiba Y, Mam B, Lukulay P, et al. The quality of antimalarial medicines in Western Cambodia: a case study along the ThaiCambodian border. Southeast Asian JTrop Med Public Health. 2013;44:349-62.

38. Palmer K, Zhou S, Ryuichi K, Low-Beer D, Fatumbi B, Samphornarann T. Cambodia National malaria programme review. Phnom Penh: WHO; 2012.

39. Gryseels C, Uk S, Erhart A, Gerrets R, Sluydts V, Durnez L, et al. Injections, cocktails and diviners: therapeutic flexibility in the context of malaria elimination and drug resistance in Northeast Cambodia. PLoS One. 2013:8:e80343.

40. Gosling J, Case P, Tulloch J, Chandramohan D, Wegbreit J, Newby G, et al. Effective program management: a cornerstone of malaria elimination. Am J Trop Med Hyg. 2015;93:135-8.

41. Kheang ST, Duong S, Olkkonen A. Increasing access to early malaria diagnosis and prompted treatment in remote cambodian villages. Am J Public Health. 2011;101:e6-8.

42. Plowe CV. The danger of untreatable malaria is real and present. Washington DC: CSIS; 2014 
43. Canavati SE. National consultative workshop on the BCC strategy for malaria elimination, vol. 1. Battambang: CNM; 2013. p. 23

44. Khamsiriwatchara A, Wangroongsarb P, Thwing J, Eliades J, Satimai W, Delacollette $C$. Respondent-driven sampling on the Thailand-Cambodia border. I. Can malaria cases be contained in mobile migrant workers? Malar J. 2011;10:120.

45. Khamsiriwatchara A, Wangroongsarb P, Thwing J, Eliades J, Satimai W, Delacollette C. Respondent-driven sampling on the Thailand-Cambodia border. II. Knowledge, perception, practice and treatment-seeking behaviour of migrants in malaria endemic zones. Malar J. 2011;10:117.

46. Hustedt J, Canavati S, Chandary Rang SU, Macom J, Po LY, Siv S, et al. The use of respondent driven sampling methods to identify malaria prevention knowledge and behaviors by migrant and mobile populations in western Cambodia. New Orleans: ASTMH; 2014.

47. Gryseels C, Durnez L, Gerrets R, Uk S, Suon S, Set S, et al. Re-imagining malaria: heterogeneity of human and mosquito behaviour in relation to residual malaria transmission in Cambodia. Malar J. 2015;14:165.

48. Peeters Grietens K, Gryseels C, Dierickx S, Bannister-Tyrrell M, Trienekens S, Uk S, et al. Characterizing types of human mobility to inform differential and targeted malaria elimination strategies in Northeast Cambodia. Sci Rep. 2015;5:16837.

49. Paintain LS, Willey B, Kedenge S, Sharkey A, Kim J, Buj V, et al. Community health workers and stand-alone or integrated case management of malaria: a systematic literature review. Am J Trop Med Hyg. 2014;91:461-70.

50. Liu A, Sullivan S, Khan M, Sachs S, Singh P. Community health workers in global health: scale and scalability. Mt Sinai J Med. 2011;78:419-35.

51. Gelade GA, Ivery M. The impact of human resource management and work climate on organizational performance. Pers Psychol. 2003;56:383-404.

52. Kulig JC, Stewart N, Penz K, Forbes D, Morgan D, Emerson P. Work setting, community attachment and satisfaction among rural and remote nurses. Public Health Nurs. 2009;26:430-9.

53. Purcell J, Hutchinson S. Front-line managers as agents in the HRM-performance causal chain: theory, analysis and evidence. Hum Resour Manag J. 2007;17:3-20
54. Frankel S, Doggett MA. The community health worker: effective programmes for developing countries. Community-based health programmes in Indonesia: the challenge of supporting a national expansion. Oxford: Oxford University Press; 1992. p. 63-87.

55. Berman PA, Gwatkin DR, Burger SE. Community-based health workers: head start or false start towards health for all? Soc Sci Med. 1987;25:443-59.

56. Perry $H$, Zulliger R. How effective are community health workers?. Baltimore: Johns Hopkins Bloomberg School of Public Health; 2012.

57. Rowe AK, de Savigny D, Lanata CF, Victora CG. How can we achieve and maintain high-quality performance of health workers in low-resource settings? Lancet. 2005;366:1026-35.

58. Franco LM, Bennett S, Kanfer R, Stubblebine P. Determinants and consequences of health worker motivation in hospitals in Jordan and Georgia. Soc Sci Med. 2004;58:343-55.

59. Jayasuriya R, Razee H, Bretnall L, Whittaker M, Yap L, Chakumai K. Voices from the field: factors influencing rural health workers performance in Papua New Guinea. Sydney: University of New South Wales; 2011.

60. Jayasuriya R, Whittaker M, Halim G, Martineau T. Rural health workers and their work environment: the role of inter-personal factors on job satisfaction of nurses in rural Papua New Guinea. BMC Health Serv Res. 2012;12:156.

61. Franco L. Health sector reform and public sector health worker motivation: a conceptual framework. Soc Sci Med. 2002;54:1255-66.

62. Manongi RN, Marchant TC, Bygbjerg IC. Improving motivation among primary health care workers in Tanzania: a health worker perspective. Hum Resour Health. 2006;4:6.

63. Mathauer I, Imhoff I. Health worker motivation in Africa: the role of non-financial incentives and human resource management tools. Hum Resour Health. 2006;4:24.

64. WHO. Global technical strategy for malaria. Geneva: World Health Organization; 2015.

\section{Submit your next manuscript to BioMed Central and we will help you at every step:}

- We accept pre-submission inquiries

- Our selector tool helps you to find the most relevant journal

- We provide round the clock customer support

- Convenient online submission

- Thorough peer review

- Inclusion in PubMed and all major indexing services

- Maximum visibility for your research

Submit your manuscript at www.biomedcentral.com/submit 